Received date: 11/26/2014

Accepted date: 05/10/2015

Revised date: 04/24/2015

Wiley received date: 05/11/2015

Article Category: Original Manuscript

Chronic Rhinosinusitis: Patient Experiences of Primary and Secondary Care A Qualitative Study

SE Erskine ${ }^{1}$, MM Verkerk $^{2}$, C Notley ${ }^{1}$, , IG Williamson ${ }^{3}$, CM Philpott $^{1,4}$

SE Erskine (Corresponding Author)

MBChB MRCS (ENT)

ST3 ENT

MM Verkerk

MBChB

FY2 ENT

C Notley

BSc Hons PhD

Senior Research Associate

IG Williamson

MBChB FRCS MD FRCGP

This article has been accepted for publication and undergone full peer review but has not been through the copyediting, typesetting, pagination and proofreading process, which may lead to differences between this version and the Version of Record. Please cite this article as doi: $10.1111 /$ coa. 12462

This article is protected by copyright. All rights reserved. 
Senior Lecturer in Primary Care

CM Philpott

MB ChB DLO FRCS(ORL-HNS) MD PGCME

Anthony Long Senior Lecturer

Honorary Consultant ENT Surgeon \& Rhinologist

1. Norwich Medical School

University of East Anglia

Norwich Research Park

Norwich

NR4 7TJ

2. Department of Otorhinolaryngology

Freeman Hospital

Freeman Road

High Heaton

Newcastle upon Tyne

NE7 7DN

3. Primary Medical Care

Aldermoor Health Centre

Aldermoor Close

Southampton

SO16 5ST

This article is protected by copyright. All rights reserved. 


\title{
4.Department of Otorhinolaryngology
}

James Paget Hospital

Lowestoft Rd

Gorleston-on-Sea

Great Yarmouth

Norfolk

NR31 6L

No competing interests.

This research received no specific grant from any funding agency in the public, commercial or not-for-profit sectors. Consumable costs were covered by the Anthony Long Trust.

No conflicts of interest

All those named above are significant contributors to either design, data collection and analysis or interpretation of results. All contributed to the final manuscript.

No additional data available.

Guarantor: Carl M Philpott

Acknowledgments:A HoweProfessor of Primary Care ${ }^{1}$

\begin{abstract}
Objectives: To explore the experience of CRS and its management from the perspective of patients with CRS. To our knowledge this is the first qualitative study exploring sinus disease.
\end{abstract}

This article is protected by copyright. All rights reserved. 
Design: Semi-structured qualitative interviews

Setting:ENT outpatient clinic

Participants: 21 adult patients with CRS: 11 male, 10 female. Patients suffered from a range of types of CRS (including polyps and fungal disease) and differing durations of symptoms (1.5- 47 years). Participants were purposively selected. Thematic analysis was used.

Outcome measures: Patient experience of CRS and its management.

Results: Patients had concerns regarding management of their symptoms by both healthcare professionals and themselves, including delays to referral and repeated medications. They reported reduced quality of life and high financial and psychosocial costs associated with living with CRS.

Conclusions: Despite guidelines for CRS treatment, outcomes remain variable leading to dissatisfaction with treatment. Adherence to existing guidelines may result in fewer repeated consultations in primary care and earlier referrals to secondary care.

Key words: General practice, nasal obstruction, quality of health care, rhinitis, paranasal sinus disease

This article is protected by copyright. All rights reserved. 
Abbreviations:

CRS - Chronic rhinosinusitis, CRSwNP - Chronic rhinosinusitis with nasal polyps, CRSsNP - Chronic rhinosinusitis without (sans) nasal polyps, AFRS - Allergic fungal rhinosinusitis

\section{Background}

Rhinosinusitis is one of the most common health problems in the Western world ${ }^{1}$ with a recent European study estimating the prevalence of chronic rhinosinusitis (CRS) at $11 \%^{2}$. It isdefined as inflammation of the nose and paranasal sinuses characterised by symptoms of nasal blockage and/or nasal discharge and may include facial pain and loss of smell according to the diagnostic criteria of the European Position Paper on Rhinosinusitis and Nasal Polyps ${ }^{3}$. Chronic disease is distinguished from acute by the persistence of symptoms for at least 12 weeks ${ }^{4}$.

Morbidity is considerable, reaching into physical, social and emotional indices of health. In addition to nasal symptoms, CRS patients consistently report lower healthrelated quality of life with adverse effects on olfaction, sleep quality, sexual function, work productivity and mental health ${ }^{5}$; these have been reported to be worse than in patients with other chronic illnesses frequently seen in primary care such as:COPD, back pain and heart failure ${ }^{6}$. The direct and indirect costs are consequently large, although as yet not quantified in a British setting.

This article is protected by copyright. All rights reserved. 
The majority of CRS is diagnosed and managed in primary care ${ }^{7}$ and is usually made on the basis of nasal symptoms alone. In secondary and tertiary care, anterior rhinoscopy, nasal endoscopy and CT scanning can be employed to confirm the diagnosis of CRS. Evidence-based treatment options for chronic rhinosinusitis include nasal irrigation with saline, intranasal or oral steroids, and oral antibiotics ${ }^{8,9}$.

The use of guideline-based treatment has been shown to improve quality of life and reduce symptoms in comparison to free-choice treatment ${ }^{10}$ and guidelines for the management of CRS have been recently updated ${ }^{3,4,11-13}$ including guidance documents specifically for primary care ${ }^{11}$. Despite suchguidelines, uptake and utilisation in primary and secondary care in the UK is not consistent ${ }^{14}$. Treatment therefore remains variable with neither primary care physicians or patients satisfied with management of sinus disease ${ }^{1516}$.

Optimum management of patients with chronic conditions is usually achieved through therapeutic partnerships with health professionals ${ }^{17}$. 'Management' in the context of chronic disease includes a patient's whole experience of an illness and treatment and is consequently often investigated through qualitative interviews allowing detailed exploration of relevant issues. It is seen as an increasingly important aspect of primary care. Yet in contrast to a wealth of qualitative literature regarding chronic conditions such as asthma ${ }^{18}$ and diabetes, this study, to the best of our knowledge, is the first study to explore the experience of CRS and its management from patients' perspectives. Some previous work has looked at the impact of allergic rhinitis; one US study found approximately $30 \%$ of physicians underestimated the severity of allergic rhinitis and its effect on work and social 
activities ${ }^{4}$. The EPOS $^{3}$ guidelines have also suggested that more work is needed to explore the impact of CRS.

\section{Methods}

Semi-structured interviews with 21 purposively selected patients attending a specialist rhinology clinic were undertaken. Patients were selected to include a range of duration and management (surgical and medical) of CRS and different subtypes of disease. They were identified from the senior author's tertiary rhinology clinic to include both new and follow-up patients. Only one patient approached declined interview as he was unable to attend during the time period of the study, March to June 2012. Whilst only patients who had been referred to secondary care were sampled for this study, all had had to pass through primary care to be referred.

This study was reviewed and approved by Oxford 'C' Ethics Committee. Participants were refunded for travel and parking and given a £20 shopping voucher for participation.

An interview template was produced; this was designed by the interviewer (SE) a qualitative researcher $(\mathrm{CN})$ and the senior author to ensure it included the broad range of concerns raised in clinic by patients. Potential concerns wereidentified by the senior author and from quality of life studies including CRS patients as well as similar research including patients with asthma, but also allowing scope for patients to raise their own concerns. The template was piloted on a patient with CRS who agreed to participate and give feedback. In line with qualitative research 
methodology, novel issues which came to light during early interviews were included in the template for subsequent interviews ${ }^{19}$.

The patients selected and the interview design were chosen to maximise the likelihood of including the greatestrange of issues of patients, known as 'maximum variation sampling', and to achieve saturation of themes during subsequent analysis $^{20}$. Patients were selected to include adult males and females across a spread of ages with different types of CRS. The exact numbers of interviews required varies greatly in qualitative research; an acceptable number of patients were included for a study of this type to saturate themes and enable meaningful analysis. The number of participants was agreed prior to the start of recruitment; this is in excess of the twelve which are generally thought to be required to achieve saturation of themes, ${ }^{20}$ but it was intended to include a heterogeneous mix of patients with CRS so a larger number was selected according to qualitative research principles $^{20-22}$ which allow flexibility to suit the type of participants, interviews and objectives of the study.

Once the study had been explained, patients could choose when to participate in the qualitative interview. Interviews were carried out in a separate room adjacent to the rhinology clinic by a clinician trained and experienced in qualitative research methods and lasted between 50 and 90 minutes. Participants could decide to have the interview on the day of their clinic appointment or come back at another time more convenient to them. This clinician undertaking the interviews was not involved directly in participants' clinical care. Interviews were recorded and transcribed. 
Thematic analysis of the transcripts was undertaken; interviews were transcribed precisely as spoken and checked against recordings for accuracy. Both frequently occurring and important themes were highlighted, considered and coded ${ }^{16,23}$.To our knowledge, there is no similar qualitative study of patients with any form of sinus disease. The aims of this analysis were therefore exploratory, to generate novel themes. It was carried out using Nvivo 10, a software package for organising the analysis of qualitative research. All transcripts were analysed by one researcher with two other researchers analysing selected transcripts to ensure consistency and reduce researcher bias.

The scope of the overall themes identified was too great in breadth to be considered with sufficient detail in one paper (see table 1). This analysis reports the factors perceived as relevant to patient care both for management in primary care, and referral to secondary care. Many participants had considerable frustrations with an aspect of CRS management so the themes contributing most to this feeling have been included here. Themes such as perceived trigger factors were considered as a separate issue by most participants and so will be considered in a following paper. The interaction between CRS symptoms and other respiratory problems was an important issue, and whilst relevant to theoverarching 'management' theme, it was an issue for specific participants only, and is related to the aetiology of their symptoms; it will therefore also be considered separately. 


\section{Results}

Participants

The age range of participants was 24-75 years with 10 females and 11 males.

Patients suffered from different types of CRS (established from clinical information and according to EPOS 2012 criteria $^{3}$ ):

CRS without nasal polyps (CRSsNP) 6, CRS with nasal polyps (CRSwNPs) 10, allergic fungal rhinosinusitis (AFRS) 5. Patient estimated duration of symptoms was 1.5 to 47 years with a mean of 19.7 and median 14.5 years.

Table 1: Showing themes and subthemes identified from analysis of all interviews. Themes in bold are considered in this analysis.

Those themes including topics relevant to access to care (bold) are discussed in more detail as follows.

\section{Symptom and duration of symptoms}

Patients described a wide range of physical symptoms.

II was just producing a lot of mucus..... I'm constantly blowing my nose and l've lost my sense of smell.' Patient 9 (Male, 55, AFRS)

'I get horrible yellow catarrh, ...just you know all the time.' Patient 2 (Female, 62, CRSwNP)

However, the onset of symptoms varied greatly. Many patients felt their symptoms had had an insidious onset, others said they could name a triggering incident or time period where symptoms had begun. 
II found that I was getting cold like symptoms every winter and year by year they seemed to be lasting longer'. Patient 9 (Male, 55, AFRS)

\section{Treatment seeking and referral}

Treatment-seeking behaviour varied greatly. Some patients had treated themselves for many years prior to seeking further treatment. Others visited their GP/ several GPs and tried a range of topical and systemic treatments. Some felt this was acceptable; others wanted a prompt referral tosecondary care when treatment or investigation was unsatisfactory.

'My one thing would be l've had them [symptoms] now for quite a few years... if it turns out that it is something [sinister] I'll be pretty miffed that I wasn't referred that long ago.' Patient 11 (Male, 34, CRSsNP)

Referral (or lack of referral) to secondary care was prompted both by GP suggestion and patient request. Reasons for onward referral included failed treatment and patient concern.

'He never referred me because I didn't consider it a really big problem.' Patient 2(Female, 62, CRSwNP)

\section{Problems with treatment}

Neither treatment in primary nor secondary care was entirely satisfactory to some patients.Sometimes this was due to unsatisfactory consultations; others felt their symptoms were not taken seriously.

This article is protected by copyright. All rights reserved. 
'I mean it's just annoying that you've got to stop work go and queue up at the GP's sit there to be told well they can't find anything.' Patient 4 (Male, 53, CRSsNP)

'No one (primary care) ever looked up my nose really to see if there was anything there.' Patient 5 (Male, 53, CRSwNP)

It was not only in primary care where patients were met with frustrations. Some of the patients found repeated consultations in an ENT clinic did not improve their problems.

'I did go on [the internet] and it did say you know if you have a good consultant they will do the allergy test, the camera and a CT scan. I never got that far so I was a little bit upset about that.' Patient 13 (Female, 58, CRSsNP)

Most described several courses of different, often ineffective treatments, which were not always reviewed.

'Everything I tried was so random.' Patient 17 (Female, 47, AFRS)

'I was put onto Betnesol nasal drops, remained on them until last year [without significant benefit. Patient had been on this treatment for 40 years]. Patient 8 (Female, 73, CRSwNP)

Others did experience improvement but found it was not sustained.

'The combination of antibiotics and steroids was very, very effective, very quickly, but it didn't last; it would just be for the time that I was taking the tablets.' Patient 17 (Female, 47, AFRS)

This article is protected by copyright. All rights reserved. 
As expected surgery often bought about more immediate benefits, although some patients were disappointed at the short lived benefits of treatment.

I've had polyps removed twice but you know it brings about marginal improvement for a while but it doesn't change the condition noticeably' Patient 9 (Male, 55, AFRS)

Many wished that they had been able to access more effective treatment more quickly.

'Actually you realise after you've had something like this [comprehensive sinus surgery] done how different you feel and to know that l've spent years of my life not really $100 \%$ well is a bit annoying.' Patient 17 (Female, 47, AFRS)

\section{Interaction with other illnesses}

Reported elsewhere ${ }^{24}$

Another issue reported was interaction with other illnesses, this may also mask diagnosis.

'My GP kept saying oh well you've got a touch of bronchitis and all kinds of things like that ... I was referred to the chest clinic... then the consultant at the chest clinic said well whilst your nose is so congested your chest will never be free so I suggest you go and see an ENT consultant.' Patient 8 (Female, 73, CRSwNP)

This article is protected by copyright. All rights reserved. 


\section{Impact on daily living}

Impact on daily life ranged hugely. CRS is a disease very rarely associated with life threatening problems but despite this, symptoms were troublesome enough to worry many patients that they had a sinister underlying pathology.

'You start worrying about various things like you know with obviously like cancer ... that does play on my mind um quite a bit at times and obviously that's a lot of the reason why I did go back to the GP. ' Patient 11 (Male, 34, CRSsNP)

Some participants did not feel their symptoms were very problematic whilst others described a bleak outlook influencing every sphere of their life.

'You get to the point where...you're quite tolerant...you'll put up (with) an awful lot as a human being, you'll just cope, but then you start to think what if I didn't have to, how would I feel, what would my life be like?' Patient 17 (Female, 47, AFRS)

"I think I was about 14 I tried to commit suicide because it got so bad it really you know it seemed like no one was helping me [although] I was going to my doctors explaining everything to him.' Patient 7 (Male, 24, CRSsNP)

Impact on work and social functioning was also impaired.

If I'm getting majorly congested my over the telephone it is awkward people ask me to repeat myself.' Patient 1 (Female, 56, CRSwNP)

This article is protected by copyright. All rights reserved. 


\section{Financial burden}

The financial impact was discussed. This related to seeking alternative treatments when conventional NHS care proved unsatisfactory.

'He's a chiropractor... I was seeing him every six weeks and his charges were pretty high... 4 to 5 thousand pounds... but it's something l'm passionate about I want as does everyone really want to find the root cause.' Patient 20 (Male, 35, AFRS)

As well as the cost of over the counter medications and prescriptions.

'Your GP should give you the whole twelve weeks in one prescription... you could have a prescription for a period of time and you'll get like seven days' worth and you're back 'I'll give you another two weeks' and then there's two things, it adds up and that's extortionate.' Patient 11 (Male, 34, CRSsNP)

\section{Discussion}

Key findings

CRS is extremely common and associated with significant morbidity but several participants felt symptoms were not necessarily taken seriously. Although treatments are available, these interviews highlight areas in which outcomes are clearly not yet satisfactory and with costs to both the individual and the economy. Diagnosis and treatment of CRS is dependent on a patient presenting, usually to their GP. This may be preceded by years of occasional medication use and recurring symptoms; patients with CRS frequently self-medicate with both over-the-counter (OTC) remedies and complementary medicines, evident in both the interviews and in larger quantitative studies ${ }^{25-27}$. This may underlie why most patients present in middle age; they have an insidious onset with gradually worsening symptoms. Some participants 
were frustrated by repeated ineffective medications and a lack of systematic management, others were not sure how to use topical nasal products. Many participants alluded to the fact that there is often no one 'cure'; better explanation by

clinicians as to the nature of CRS may make ongoing medical treatment more understandable and acceptable. The degree of morbidity experienced vary widely from feeling congested to feeling suicidal. Patients had often shouldered significant financial burden in managing their CRS, not only through missing work due to poorly controlled symptoms but also when trying alternative therapies (with little evidence base) or looking for private health advise when they felt their NHS care had not been adequate.

\section{Strengths and limitations}

Involvement of patients in their own healthcare is increasingly recognised as important; these interviews are unique in allowing patients to raise their own concerns regarding management of CRS in a research setting. The themes are likely to resonate strongly with many clinicians' clinical experiences. The wide range of participants ensures that themes associated with experience of CRS and management are as broad as possible althoughresults are not necessarily generalizable to a wider population. Participants were asked whether they would like to participate in the study following their consultation about their CRS; they may have felt obliged to participate, the risk of this was minimised as the person conducting the studies was not directly involved in the particpants' care.

This article is protected by copyright. All rights reserved. 


\section{Comparison with other studies}

Few studies have directly addressed concerns of patients with CRS; this study allowed patients to discuss any issues surrounding CRS and its management which they felt are important. Our study reflects current literature in the great variation of experience of diagnostic tests and treatment in both primary and secondary care, with geographic variation as well variation between clinicians in the same centre ${ }^{7,10}$, 28 .

The existing literature paints a discordant picture between management of CRS recommended by specialists and reality. Few studies have directly addressed this issue, but the causes appear to be multilevel: patient concerns and expectations, variations in clinical practice, physician and patient education and health infrastructure may all feed into patterns of behaviour that contribute to sub-optimal outcomes with current management of this disease.A cross-sectional European survey of 2966 patients suggested that patients with allergic rhinitis tended to either self-medicate or present to the GP in order to request a specific treatment, rather than to have a two-way discussion about appropriate management ${ }^{29}$ presenting the first of several obstacles to successful treatment. One clinical series in California found use of complementary and alternative medicine in as many as $43 \%$ of patients with a diagnosis of CRS, including dietary modifications, herbal therapy, acupuncture, homeopathy and chiropractice ${ }^{25}$. Whilst such strategies may prove effective for some, a lack of good quality advice or guidance from healthcare professionals may mean patients suffer unnecessarily or turn to alternative medical therapies with little or no foundations in evidence ${ }^{12,30}$.

This article is protected by copyright. All rights reserved. 
Other potential problems include short consultation times, lack of post-graduate training in ENT and/or allergy, lack of access to or lack of expertise in diagnostic tests; and uncertainty over when to refer to secondary or tertiary care ${ }^{31}$. One study of 188 GPs with an interest in allergy and respiratory disorders found that only $0.6 \%$ instigated appropriate management of treatment for allergic rhinitis ${ }^{18}$. Additionally, there may be a discrepancy between physician and patient attitudes towards the severity of disease and treatment options ${ }^{4}$. For example, intranasal corticosteroids (INCs) have become established as first-line agents in the management of CRS. Whilst concerns over the side effects of oral steroids initially limited their widespread use, a multitude of randomised controlled trials have demonstrated the safety and efficacy of intranasal steroids. Both GPs and ENT surgeons frequently prescribe INCs but recent studies suggest significant concerns still exist amongst patients regarding INCs and damage to the nose, systemic side effects and addiction ${ }^{32}$. Lifestyle factors are poorly understood; they will be further investigated by this study group as part of a large multi-centre questionnaire study, the Chronic Rhinosinusitis Epidemiology Study (CRES).

Many patients interviewed were frustrated with short courses of antibiotic or other treatment which had nil, or no sustained effect. GP prescribing of antibiotics was found to reach $74 \%$ in 'sinus' type complaints in one Dutch study ${ }^{31}$ with higher rates of prescribing associated with lower GP knowledge of respiratory tract infections, lower perceived time available for consultation and with longer duration of the GP's practice. A similar picture is likely to be found amongst GPs in the UK, despite neither BSACI guidelines ${ }^{13}$ nor EPOS guidelines recommending antibiotics use by GPs for CRS ${ }^{11}$. Variation in surgical management was similarly great; 
analysis of Hospital Episode Statistic (HES) data to encapsulate the picture at Primary Care Trust (PCT) level in the NHS, shows greater than five-fold variation in maximum and minimum surgical intervention rates, after standardisation by age and gender, ranging between 2.5 sinonasal procedures per 100,000 population per annum in London to 13.5 in Devon and Cornwall ${ }^{33}$.

\section{Implications for research and/or practice}

Adherence to the EPOS guidelines would streamline management; commissioning guidelines from ENT-UK show clear treatment and referral pathways from primary care $^{34}$. Correct treatment can only follow a correct diagnosis; it is known that nasal endoscopy improves the accuracy of a diagnosis of sinusitis, but it is acknowledged that widespread use in primary care would not be feasible ${ }^{8}$. Thus it is more important that referral to secondary care is undertaken if there is no symptomatic response to 3 months of topical treatment; this did not always occur for our participants due to both patient and clinician preferences. One participant mentioned that no one had looked in his nose prior to referral to secondary care; basic anterior rhinoscopy may be feasible and helpful in primary care settings.

The likely duration of treatment should be discussed and include the possibility of the need for treatment to be lifelong, to help manage both expectations of the outcome of treatment and to aid management of the financial burden of medication. Time should be taken to explain how to use topical treatments to maximise their effect.

This article is protected by copyright. All rights reserved. 
The formal synthesis of patients' views highlights the need for research to better understand CRS and its management. Given the popularity of self-medication, this this may include alteration of service provision away from the clinician towards community pharmacy and non-clinicians. It will become increasingly important to quantify the financial burden of CRS both to individuals and to the NHS. Efficient care is needed and is likely to be improved by better use of current guidelines ${ }^{3}, 35$. Research is also needed to clarify our understanding of the epidemiology of CRS to enable development of more effective medical and surgical treatments; these data support such research proposals.

Our study underlines the wide range of morbidity associated with CRS as well as potential weaknesses in management pathways. Reflecting on such concerns and considering them when managing patients with CRS will improve care for such individuals.

Funding: This research received no specific grant from any funding agency in the public, commercial or not-for-profit sectors. Consumable costs were covered by the Anthony Long Trust.

Words: 2512excluding patient quotations (3581 including)

This article is protected by copyright. All rights reserved. 


\section{References}

1. Benninger MS, Ferguson BJ, Hadley JA, et al. Adult chronic rhinosinusitis: definitions, diagnosis, epidemiology, and pathophysiology. Otolaryngology--head and neck surgery : official journal of American Academy of Otolaryngology-Head and Neck Surgery. [Research Support, Non-U.S. Gov't

Review]. 2003 Sep;129(3 Suppl):S1-32.

2. Hastan D, Fokkens WJ, Bachert C, et al. Chronic rhinosinusitis in Europe--an underestimated disease. A GA(2)LEN study. Allergy. 2011 Sep;66(9):1216-23.

3. Fokkens W, Lund V, Mullol J. EPOS 2012: European position paper on rhinosinusitis and nasal polyps. Rhinology. 2012;50(1):1-12.

4. Meltzer EO. Allergic rhinitis: the impact of discordant perspectives of patient and physician on treatment decisions. Clinical therapeutics. 2007 Jul;29(7):1428-40.

5. Rudmik L, Smith TL. Quality of life in patients with chronic rhinosinusitis. Current allergy and asthma reports. 2011 Jun;11(3):247-52.

6. Gliklich RE, Metson R. The health impact of chronic sinusitis in patients seeking otolaryngologic care. Otolaryngol Head Neck Surg. 1995 Jul;113(1):104-9.

7. Lee LN, Bhattacharyya N. Regional and specialty variations in the treatment of chronic rhinosinusitis. The Laryngoscope. 2011 May;121(5):1092-7.

8. Ah-See KL, MacKenzie J, Ah-See KW. Management of chronic rhinosinusitis. BMJ (Clinical research ed). 2012;345:e7054.

9. Fokkens WJ, Lund VJ, Mullol J, et al. EPOS 2012: European position paper on rhinosinusitis and nasal polyps 2012. A summary for otorhinolaryngologists. Rhinology. 2012 Mar;50(1):1-12.

10. Costa DJ, Bousquet PJ, Ryan D, et al. Guidelines for allergic rhinitis need to be used in primary care. Primary care respiratory journal : journal of the General Practice Airways Group. 2009 Dec;18(4):250-7.

11. Thomas M, Yawn BP, Price D, et al. EPOS Primary Care Guidelines: European Position Paper on the Primary Care Diagnosis and Management of Rhinosinusitis and Nasal Polyps 2007 - a summary. Primary care respiratory journal : journal of the General Practice Airways Group. 2008 Jun;17(2):79-89.

12. Scadding GK, Durham SR, Mirakian R, et al. BSACI guidelines for the management of allergic and non-allergic rhinitis. Clinical and experimental allergy : journal of the British Society for Allergy and Clinical Immunology. 2008 Jan;38(1):19-42.

13. Angier E, Willington J, Scadding G, Holmes S, Walker S. Management of allergic and non-allergic rhinitis: a primary care summary of the BSACI guideline. Primary Care Respiratory Journal. 2010;19(3):217-22.

14. Su N, Cheang PP, Khalil H. Do rhinology care pathways in primary care influence the quality of referrals to secondary care? The Journal of Laryngology \& Otology. 2013;127(04):364-7.

15. Scadding GK, Richards DH, Price MJ. Patient and physician perspectives on the impact and management of perennial and seasonal allergic rhinitis. Clinical Otolaryngology \& Allied Sciences. 2000;25(6):551-7.

16. Braun V, Clarke V. Using thematic analysis in psychology. Qualitative Research in Psychology. 2006;3(2):77-101.

17. Tan BK, Chandra RK, Pollak J, et al. Incidence and associated premorbid diagnoses of patients with chronic rhinosinusitis. The Journal of allergy and clinical immunology. 2013.

This article is protected by copyright. All rights reserved. 
18. Ryan D, Grant-Casey J, Scadding G, et al. Management of allergic rhinitis in UK primary care: baseline audit. Primary Care Respiratory Journal. 2005;14(4):204-9. 19. Turner DW. Qualitative Interview Design: A Practical Guide for Novice Investigators. The Qualitative Report 2010;15(3):754-60.

20. Guest G, Bunce A, Johnson L. How Many Interviews Are Enough?: An Experiment with Data Saturation and Variability. Field Methods. 2006 February 1, 2006;18(1):5982.

21. Sandelowski M. Sample size in qualitative research. Research in Nursing \& Health. 1995;18(2):179-83.

22. Baker SE, Edwards R. How many qualitative interviews is enough? Expert voices and early career reflections on sampling and cases in qualitative research. National Centre for Research Methods Review Paper2012.

23. Buetow S. Thematic analysis and its reconceptualization as 'saliency analysis'. Journal of health services research \& policy. 2010 Apr;15(2):123-5.

24. Erskine SE, Notley C, Wilson AM, Philpott CM. Managing chronic rhinosinusitis and respiratory disease: a qualitative study of triggers and interactions. Journal of Asthma.0(0):1-6.

25. Blanc PD, Trupin L, Earnest G, et al. Alternative therapies among adults with a reported diagnosis of asthma or rhinosinusitis : data from a population-based survey. Chest. [Research Support, U.S. Gov't, P.H.S.]. 2001 Nov;120(5):1461-7.

26. Canonica GW, Bousquet J, Mullol J, Scadding GK, Virchow JC. A survey of the burden of allergic rhinitis in Europe. Allergy. 2007;62 Suppl 85:17-25.

27. Krouse JH, Krouse HJ. Patient use of traditional and complementary therapies in treating rhinosinusitis before consulting an otolaryngologist. The Laryngoscope. 1999 Aug;109(8):1223-7.

28. Bhattacharyya N. Contemporary assessment of the disease burden of sinusitis. American journal of rhinology \& allergy. 2009 Jul-Aug;23(4):392-5.

29. Maurer M, Zuberbier T. Undertreatment of rhinitis symptoms in Europe: findings from a cross-sectional questionnaire survey. Allergy. 2007 Sep;62(9):1057-63.

30. Storms W, Meltzer E0, Nathan RA, Seiner JC. Allergic rhinitis: The patient's perspective. The Journal of allergy and clinical immunology. 1997;99(6):S825-S8. 31. Akkerman AE, Kuyvenhoven MM, van der Wouden JC, Verheij TJ. Prescribing antibiotics for respiratory tract infections by GPs: management and prescriber characteristics. The British journal of general practice : the journal of the Royal College of General Practitioners. 2005 Feb;55(511):114-8.

32. Hellings PW, Dobbels F, Denhaerynck K, et al. Explorative study on patient's perceived knowledge level, expectations, preferences and fear of side effects for treatment for allergic rhinitis. Clinical and translational allergy. 2012;2(1):9.

33. Health and Social Care Information Centre. Hospital Episode Statistics. 2015 [cited 2015]; Available from: http://www.hscic.gov.uk/hes.

34. ENT-UK. Commissioning Guide: Rhinosinusitis2013.

35. Contopoulos-Ioannidis DG, Koliofoti ID, Koutroumpa IC, Giannakakis IA, Ioannidis JP. Pathways for inappropriate dispensing of antibiotics for rhinosinusitis: a randomized trial. Clinical infectious diseases : an official publication of the Infectious Diseases Society of America. 2001 Jul 1;33(1):76-82.

This article is protected by copyright. All rights reserved. 
Table 1 - Themes raised

\begin{tabular}{|c|c|}
\hline Themes raised & \\
\hline $\begin{array}{l}\text { Perceived triggering factors } \\
\text { Environmental }\end{array}$ & $\begin{array}{l}\text { Impact on daily living } \\
\text { Sleep }\end{array}$ \\
\hline Dietary & Anosmia \\
\hline Family history & Work and social functions \\
\hline Symptoms & Relationships \\
\hline Duration of symptoms & Interaction with other illnesses \\
\hline Treatment seeking & Asthma \\
\hline Self-treatment & Need for integrated management with \\
\hline Delayed referral & other specialties (allergy, respiratory) \\
\hline Problems with treatment & Financial burden \\
\hline Repeated or unsuccessful medical & Cost of treatment \\
\hline treatments, often costly & Missed work \\
\hline Continuity of care & \\
\hline Lifelong treatment & \\
\hline Side effects and limitations of surgery & \\
\hline
\end{tabular}

This article is protected by copyright. All rights reserved. 